\title{
Intestinal adenoma formation and $M Y C$ activation are regulated by cooperation between MYB and Wnt signaling
}

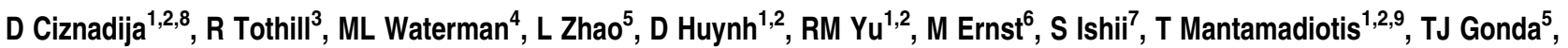 \\ RG Ramsay ${ }^{\star, 1,2}$ and $\mathrm{J}$ Malaterre ${ }^{1}$
}

\begin{abstract}
Aberrant Wnt signaling mediated by mutations affecting APC (adenomatous polyposis coli) or $\beta$-catenin initiates the majority of human colorectal cancers (CRC) and drives tumorigenesis through the activation of specific genes such as MYC. We report here a novel association whereby another oncogenic transcription factor, MYB/c-Myb, is necessary for intestinal adenoma development directed by activated Wnt signaling. $A P C^{\mathrm{Min} /+}$ mice in which $c-m y b$ is haploinsufficient survive longer than wildtype $A P C^{M i n /+}$ animals due to a delay in adenoma formation. Intestinal adenomas from $A P C^{M i n /+}$ mice were assessed and found to have high levels of $c$-myc gene expression. We explored the relationship between activated Wnt signaling and MYB in regulating $M Y C$ and found activated $\beta$-catenin in combination with MYB induces robust upregulation of $M Y C$ promoter activity, as well as endogenous MYC mRNA and protein expression, in human cells. This cooperation occurred through independent binding of MYB and $\beta$-catenin to the MYC promoter. These data highlight a cooperative function for MYB in the context of activated Wnt signaling and provide a molecular basis for the expression of MYC in CRC.
\end{abstract}

Cell Death and Differentiation (2009) 16, 1530-1538; doi:10.1038/cdd.2009.94; published online 17 July 2009

Robust expression of the transcription factor MYB/c-Myb is principally restricted to immature cells in the hemopoietic system and colon epithelium. Experiments in $c$-myb mutant mice show that two copies of the $c$-myb gene are required for cell survival during emergency responses to cytotoxic damage in both these compartments. ${ }^{1}$ In addition, colonspecific loss of Myb disrupts not only colon formation in the developing mouse, but also crypt homeostasis in adults. ${ }^{2}$ Levels of MYB expression become progressively higher as human colonic epithelium undergoes transformation whereas persistent expression blocks cytodifferentiation in both mouse and human colon cells. A large number of colorectal cancer (CRC) cell lines and clinical samples show elevated levels of MYB, with altered transcriptional elongation control underpinning this increase. ${ }^{1}$ Nevertheless, in the context of CRC development, the primary focus in both mouse and human cells has been on canonical Wnt signaling through $\beta$-catenin activation.

$\beta$-Catenin is normally targeted for degradation by a complex of proteins including APC, AXIN, and glycogen synthase kinase- $3 \beta .^{3,4}$ Wnt binding to its receptor disrupts this complex and leads to the cytoplasmic stabilization of de novo synthesized and non-phosphorylated $\beta$-catenin. ${ }^{5} \beta$-Catenin subsequently translocates to the nucleus where it associates with TCF/LEF factors. This partnership converts $\beta$-catenin into a transcriptional activator and enhances the expression of Wnt target genes, such as MYC and CYCLIND1, which in turn promote colon transformation. A number of reports indicate that mutations in $A P C$ or $C T N N B 1$ ( $\beta$-catenin) initiate the majority of $\mathrm{CRC}$. $^{6-9}$

Given that a significant proportion of CRC isolates overexpress MYB and that this likely occurs in a background of activated Wnt signaling, we considered the contribution that MYB makes to CRC development initiated by Wnt pathway activation. We report here the convergence of MYB expression with Wnt signaling in regulating intestinal adenoma formation. In vivo mouse studies showed that reduced c-myb expression positively affects survival and that c-myb expression is a necessary feature of the carcinogenic process initiated by activated Wnt signaling. Further, to understand how c-Myb is contributing to CRC formation, expression profiling studies were undertaken, confirming a significant correlation between $c$-myb and $c$-myc expression in adenomas from $A P C^{\mathrm{Min} /+}$ mice and in human $\mathrm{CRC}$. As the human $M Y C$ and mouse $c$-myc promoter landscapes are rich with previously characterized TCF/LEF and MYB binding sites, we

${ }^{1}$ Differentiation and Transcription Laboratory, Peter MacCallum Cancer Centre, East Melbourne, Victoria, Australia; ${ }^{2}$ Department of Pathology, The University of Melbourne, Parkville, Victoria, Australia; ${ }^{3}$ Cancer Genomics and Genetics Laboratory, Peter MacCallum Cancer Centre, East Melbourne, Victoria, Australia; ${ }^{4}$ Department of Microbiology and Molecular Genetics, University of California, Irvine, CA, USA; ${ }^{5}$ Diamantina Institute for Cancer, Immunology and Metabolic Medicine, University of Queensland, Brisbane, Queensland, Australia; ${ }^{6}$ Melbourne Tumour Biology Branch, Ludwig Institute for Medical Research, Royal Melbourne Hospital, Parkville, Victoria, Australia and ${ }^{7}$ Laboratory of Molecular Genetics, RIKEN Tsukuba Institute, Tsukuba, Ibaraki, Japan

*Corresponding author: RG Ramsay, Differentiation and Transcription Laboratory, Peter MacCallum Cancer Centre, St Andrews Place, East Melbourne, Victoria, 3002, Australia. Tel: + 6139656 1863; Fax: + 6139656 1411; E-mail: rob.ramsay@ petermac.org

${ }^{8}$ Current address: Department of Molecular Biology, Memorial Sloan-Kettering Cancer Center, New York, NY, USA.

${ }^{9}$ Current address: Laboratory of Physiology, Medical School, University of Patras, Patras, Greece.

Keywords: $\beta$-catenin; MYB; MYC; colon cancer; APC; min mice

Abbreviations: APC, adenomatous polyposis coli; FAP, familal adenomatous polyposis; ChIP, chromatin immunoprecipitation

Received 15.10.08; revised 03.6.09; accepted 11.6.09; Edited by KH Vousden; published online 17.7.09 
explored the possibility that MYB cooperates with $\beta$-catenin to activate $M Y C$ transcription directly. Molecular analysis confirmed that MYB and $\beta$-catenin are required in concert to enhance activation of reporters containing the human $M Y C$ promoter. This effect was mirrored when endogenous $M Y C$ gene expression was followed and occurred through the binding of both factors to the MYC promoter. These binding events induced distinct changes in histone acetylation. These findings thus further the paradigm of intestinal adenoma development through Wnt pathway activation by demonstrating the need for MYB as an accessory factor to drive MYC overexpression and subsequent colonic neoplasia.

\section{Results}

Maximum adenoma formation in $\mathrm{APC}^{\mathrm{Min} /+}$ mice is $\mathbf{c}-\mathbf{m y b}$ dependent. To explore the potential relationship between MYB and Wnt signaling in CRC development, we took a genetic approach whereby $A P C^{\mathrm{Min} /+}$ mice were crossed with $M y b^{+/-}$mice, extending the observation that $A P C^{M i n /+}$ mice have a prolonged life span when crossed onto a $c-m y c^{+/-}$ background. ${ }^{10}$ Although $A P C^{\mathrm{Min} /+}$ mice started to show signs of distress by week 10 , including wasting and bleeding from the anus, $A P C^{\mathrm{Min} /+}$ mice on a $c-m y b^{+/-}$background showed delayed onset of symptoms. When equal numbers of $A P C^{\mathrm{Min} /+}$ male and female mice were followed over time, $A P C^{\mathrm{Min} /+}$ mice on a $c-m y b^{+/-}$background survived significantly longer before developing symptoms severe enough to require mandatory killing $(P=0.01$; unpaired $t$-test) (Figure 1a). On average these mice survived beyond the death of all mice in the $A P C^{\mathrm{Min} /+}$ cohort $(P=0.03$; logrank (Mantel-Cox) test) (Figure $1 \mathrm{~b})$. These results clearly demonstrate that c-Myb is a critical determinant of adenoma progression initiated through the deregulation of Wnt signaling.

Coordinate expression of $c-m y b$ and $c-m y c$ in adenomas from $\boldsymbol{A P C} \boldsymbol{C}^{\mathrm{Min} /+}$ mice. It is evident that factors such as activated $\beta$-catenin and MYB promote tumorigenesis by regulating the activity of specific genes, particularly those having well-established functions in the carcinogenic process such as CYCLIND1, MYC, and COX-2.,11-13 Specifically, many studies point to the involvement of $\beta$-catenin in the activation of $M Y C$ in $\mathrm{CRC}$, whereas activation of the human $M Y C$ promoter and endogenous gene by $M Y B / c-M y b$ has also been established. ${ }^{14,15}$ To continue exploring the relationship between activated Wnt signaling and $M Y B$, we used real-time PCR to assess expression of $c$-myc in intestinal adenomas developing in $A P C^{\mathrm{Min} /+}$ mice (Figure 1c). As expected from previous analyses, $c-m y c$ mRNA expression was markedly increased in adenomas from both the colon and small intestine (SI). ${ }^{10,16}$ Furthermore, consistent with earlier reports and data from our own lab, c-myb mRNA expression was similarly elevated in adenomas from both sites (Figure 1d).

As $c$-myb haploinsufficiency significantly impeded the rate of adenoma formation in $A P C^{\mathrm{Min} /+}$ mice and $c$-myc expression concordantly increased in these adenomas, the relative levels $c$-myc mRNA in adenomas formed in $A P C^{\mathrm{Min} /+} \times$ $c-m y b^{+/-}$mice were accordingly investigated. In a series of adenomas taken from both the SI and colon of double heterozygous mice, $c-m y c$ levels were significantly lower than in an equivalent series removed from $A P C^{\mathrm{Min} /+}$ mice $(P<0.0001$ and $<0.006$, respectively). Furthermore, $c-m y b$
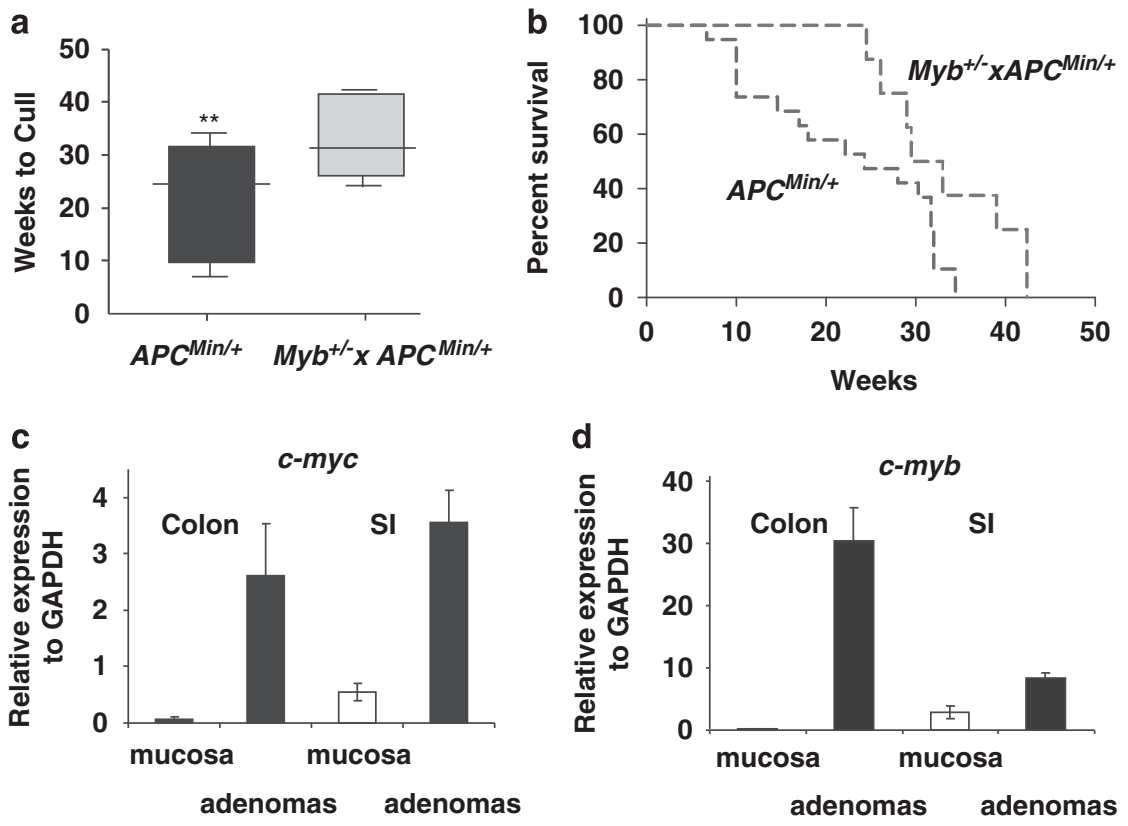

Figure 1 Two normal c-myb alleles are required for the rapid development of adenomas in $A P C^{\mathrm{min} /+}$ mice. When $A P C^{\mathrm{min} /+}$ mice were crossed onto a $c-m y b^{+/-}$ background the weeks to killing was extended significantly $(P=0.01)(a)$. Accordingly a Kaplan-Meier plot also indicates that survival is increased on a $c-m y b$ heterozygous background $(P=0.03)(\mathbf{b})$. The analysis of mRNA levels for c-myc (c) and c-myb (d) for adenomas from APC ${ }^{\mathrm{min} /+}$ mice (35 colon, 8 mice; $44 \mathrm{SI}, 6$ mice) and histologically normal mucosa ( 3 colon; $4 \mathrm{SI}$ ) dissected from $A P C^{\mathrm{min} /+}$ mice was conducted and assessed by quantitative real-time RT-PCR 
expression was also significantly decreased in these adenomas $(P>0.0001)$ (Supplementary Figure 1$)$.

MYC expression correlates with MYB expression in human CRC. To link these expression data from adenomaprone $A P C^{\mathrm{Min} /+}$ mice to human CRC, mRNA expression analysis of 229 tumor samples belonging to 13 histological types, including colon, was performed focusing on $M Y B$ and $M Y C$ and standardized against an 11-cell-line set frequently used for this type of comparison. ${ }^{17}$ These data, represented by a fold expression plot, emphasized consistently high MYB expression in CRC, as well as breast and gastric cancers (Figure 2a). When data for MYB and $M Y C$ were analyzed for each CRC alone and plotted for relative expression, an apparent association between $M Y B$ and $M Y C$ expression was evident (Figure $2 \mathrm{~b}$ ). The relative expression of $\beta$-catenin mRNA was also plotted to highlight the lack of correlation between the expression level of this gene and MYC (Figure $2 \mathrm{~b}$ ). This is consistent with literature showing that the mode of activation for $\beta$-catenin is typically at the level of protein abundance and/or localization rather than increases in mRNA expression levels. ${ }^{3,4}$

A correlation coefficient of $r=0.51$ between $M Y B$ and $M Y C$ expression in CRC was calculated using the cDNA microarray data from $23 \mathrm{CRC}$ specimens (Figure 2c, Pearson's correlation; $r=0.51, P=0.014)$. By contrast, the value for
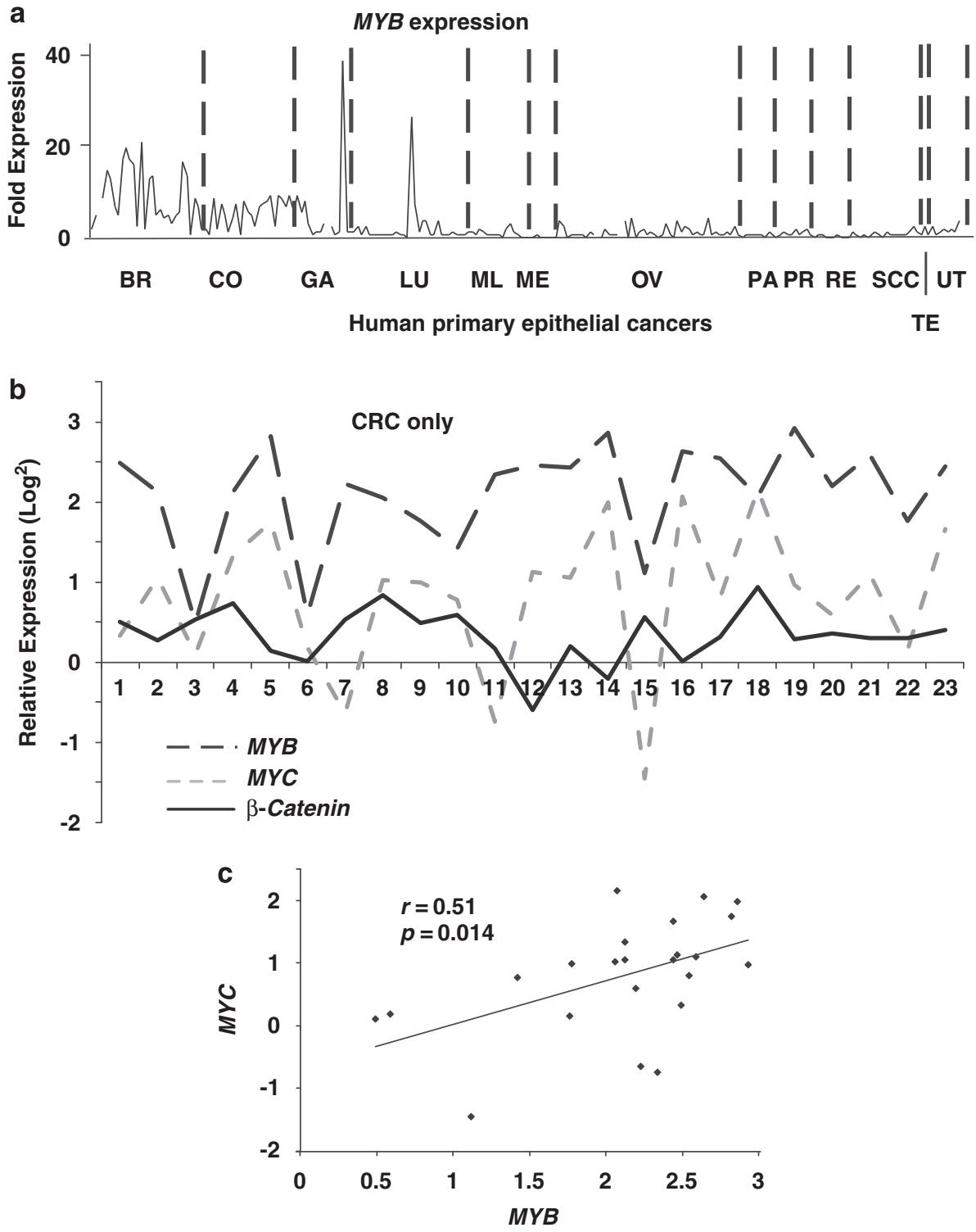

Figure $2 M Y B$ is overexpressed in colorectal (CRC) and breast carcinomas. (a) A microarray gene expression analysis was performed for MYB. Fold expression of MYB in a range of epithelial cancers was compared to an 11-cell-line pooled control. The 13 tumor types are as follows: BR, breast; CO, colon; GA, gastric; LU, lung; ML, melanoma; ME, mesothelioma; OV, ovarian; PA, pancreas; PR, prostate; RE, renal; SCC, squamous-cell carcinoma; TE, testicular; UT, uterine. (b) The relative expression of MYB, MYC, and $\beta$-catenin for $23 \mathrm{CRC}$ specimens was plotted to give an indication of whether there was an association between these three genes. (c) Using the cDNA microarray data, we calculated a Pearson's correlation ( $r=0.51 ; P=0.014$ ) between $M Y B$ (median signal from two features on the array) and $M Y C$ (representing a single feature on the array) suggesting a there is a significant correlation between the two genes 
coexpression of $M Y B$ and $M Y C$ in all other cancers was 17-fold lower ( $r=0.03, P=0.651)$, indicating that the observed correlation between $M Y B$ and $M Y C$ is highly significant in human $\mathrm{CRC}$ compared to 12 other cancer types.

SiRNA knockdown of $M Y B$ reduces $M Y C$ expression in CRC cells. In view of the observations that MYB and MYC were coordinately upregulated in adenomas developing in $A P C^{\mathrm{Min} /+}$ mice and coexpressed in human CRC where mutations in APC prevail, we pursued the relationship between $M Y B$ and $M Y C$ in a context of activated Wnt signaling. Although $M Y B$ and $M Y C$ are commonly overexpressed in CRC cells, the potential dependency of $M Y C$ expression on $M Y B$ has not been explored in this cancer type. We therefore used lentivirus infection to generate stable pools of Colo201 CRC cells that expressed either a doxycycline-inducible shRNA against $M Y B$ or a scrambled sequence control. Colo201 CRC cells express robust levels of MYB and MYC and also harbor activating mutations in the Wnt pathway. ${ }^{18,19}$ When $M Y B$ expression in this cell line is inhibited by induction of the shRNA (Figure 3a), we observed a corresponding decline in MYC expression (Figure 3b). Notably, the scrambled sequence control also led to some reduction in $M Y B$ expression when in the presence of doxycycline. The basis for this was unclear, but again emphasized that $M Y C$ expression levels in a background of activated Wnt signaling are influenced by the presence of MYB. Taken together, our results suggest involvement of $M Y B$ in the maintenance of MYC expression in CRC cells where canonical Wnt pathway mutations are also present.

$\beta$-Catenin does not induce MYB expression. The common upregulation of $M Y B$ and $M Y C$ in both CRC cells and murine adenomas harboring Wnt pathway activation suggested the possibility that in addition to $M Y C$, activated $\beta$-catenin may also directly regulate $M Y B$. This was particularly relevant in light of another study proposing that MYB is a target of the Wnt pathway. ${ }^{20}$ However, despite the presence of prospective TCF/LEF binding sites in the human and mouse $M Y B$ promoter (Supplementary Figure $2 \mathrm{a}-\mathrm{c})$ we were unable to show upregulation of the $M Y B$ promoter in the presence of an activated form of $\beta$-catenin lacking the first 89 amino acids. Strikingly, high concentrations of activated $\beta$-catenin plasmid inhibited $M Y B$ promoter activity (Figure $4 \mathrm{a}$ ). It is unclear whether this represents direct repression or the sequestration of transcription factors required for basal MYB promoter activity. In contrast, c-Myb induced its own promoter, consistent with previous findings. ${ }^{21}$ Furthermore, endogenous c-Myb/MYB activity in HEK293 and NIH3T3 cells was unaffected by exogenous activated $\beta$-catenin (Figure $4 \mathrm{~b}$; Supplementary Figure $2 \mathrm{~d}$ ), although luciferase reporter assays with the archetypal $\beta$-catenin-responsive reporter pTOPFlash showed that the construct used for these assays had transactivation function. Taken together, these results show that the correlation between $M Y B$ and $M Y C$ expression in CRC is unlikely to be due to the common activation of both genes by deregulated Wnt signaling.

MYB and activated $\beta$-catenin cooperate to induce $M Y C$ reporter activation. Considering the mutual activation of $\beta$-catenin and MYB in CRC, in addition to MYC overexpression, we next considered whether MYB and activated $\beta$-catenin share $M Y C$ as a common gene target. This was assessed using chloramphenicol acetyltransferase (CAT) reporter assays with the human MYC promoter in HEK293 epithelial cells. HEK293 cells were used as they express very low levels of MYB while retaining a functional Wnt pathway. MYB conferred a dose-dependent increase in transcription from the $M Y C$ promoter, with a maximum level of 4.0 -fold activation observed (Figure $5 \mathrm{a}$ ). It is also notable that increasing c-Myb beyond this maximum level leads to a progressive decline in reporter activation. ${ }^{14}$ When similar levels of activated $\beta$-catenin were co-transfected with the $M Y C$ promoter, there was a more modest effect on reporter activity compared with c-Myb alone, with a twofold increase observed at best, in keeping with previous analyses (Figure 5b). ${ }^{11}$

The prominence of binding sites for both MYB and the $\beta$-catenin transcriptional partner TCF/LEF within the MYC promoter sequence indicates a possible convergence of these pathways in the activation of $M Y C$. As expected from the previous dose-response curves, transfection of
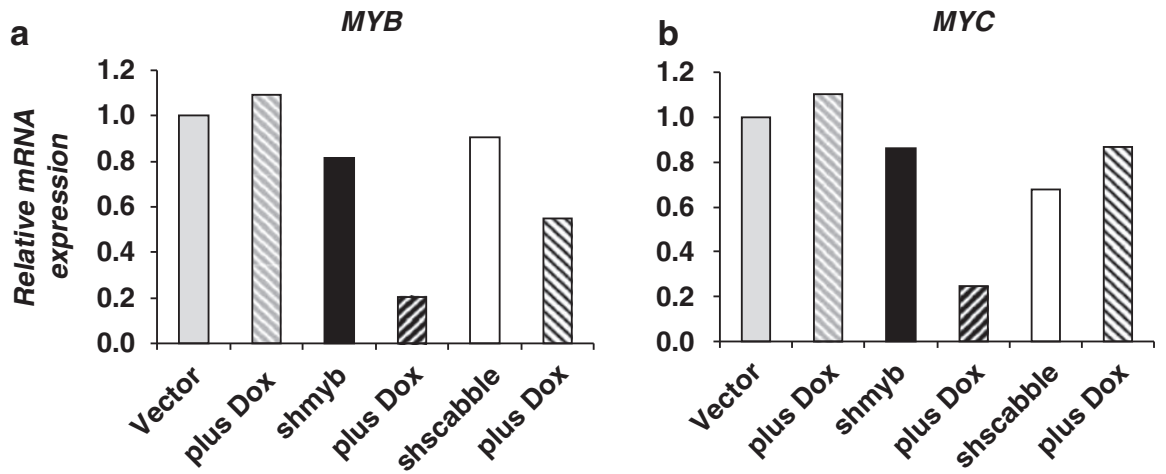

Figure 3 shRNA against MYB downregulates MYC expression in CRC cells. Stable cell line pools of Colo201 cells that expressed doxycycline-inducible shRNA against $M Y B$, a scrabbled shRNA, or vector control were generated by lentivirus infection. Colo201 CRC cells express robust levels of both genes and when MYB expression is reduced (a) by shmyb following $24 \mathrm{~h}$ induction by doxycycline we observed a corresponding reduction in MYC expression (b). The mean expression levels based on two separate cDNA syntheses and real-time RT-PCRs conducted in triplicate in both cases are shown 
a

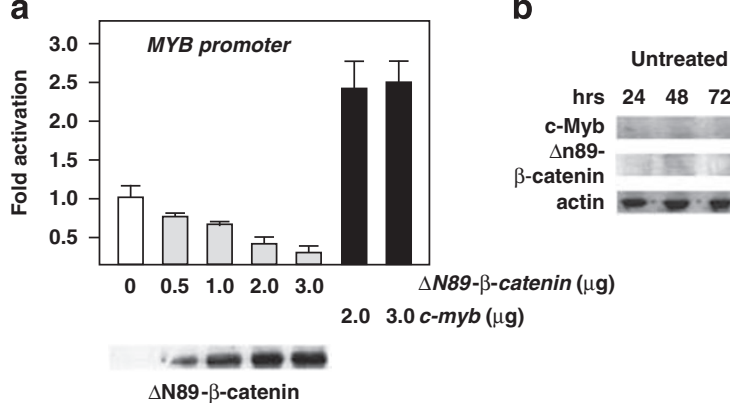

3ug

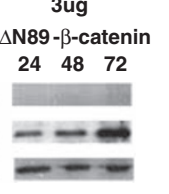

C 18

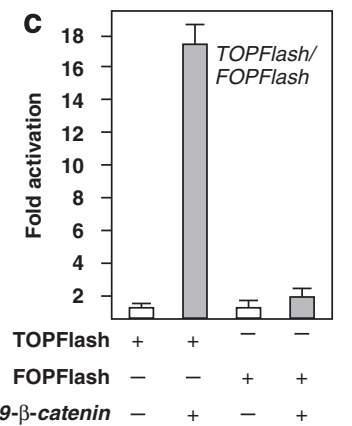

Figure 4 Activated $\beta$-catenin is unable to stimulate either MYB promoter activity or endogenous MYB expression in HEK293 epithelial cells. (a) Cells were transfected with the reporter pMBS-CAT (harboring the multiple c-Myb binding sites) and increasing amounts of either full-length c-Myb (pACT-c-myb) or activated $\beta$-catenin (pcDNA3.1$\triangle N 89-\beta$-catenin). After $72 \mathrm{~h}$, cells were harvested, lysed, and assessed for CAT enzyme activity. Mean \pm S.E.M. of quadruplicate experiments is shown. Western blots depicting the expression of the effector proteins in the transfected cells are presented below the graphs from one of the replicate experiments. (b) HEK293 cells were transfected with activated $\beta$-catenin and $72 \mathrm{~h}$ later, harvested, lysed, and assessed for c-Myb and transfected $\beta$-catenin by western blot. Pan actin is shown as a loading control. (c) The ability of activated $\beta$-catenin to stimulate the luciferase reporters, pTOPFlash and pFOPFlash, is shown. HEK293 cells were transfected with $1 \mu \mathrm{g}$ of either pTOPFlash or pFOPFlash reporter, along with $2 \mu \mathrm{g}$ of activated $\beta$-catenin and the amount of luciferase activity in cells was measured $72 \mathrm{~h}$ after transfection. Mean \pm S.E.M. of triplicate experiments is shown
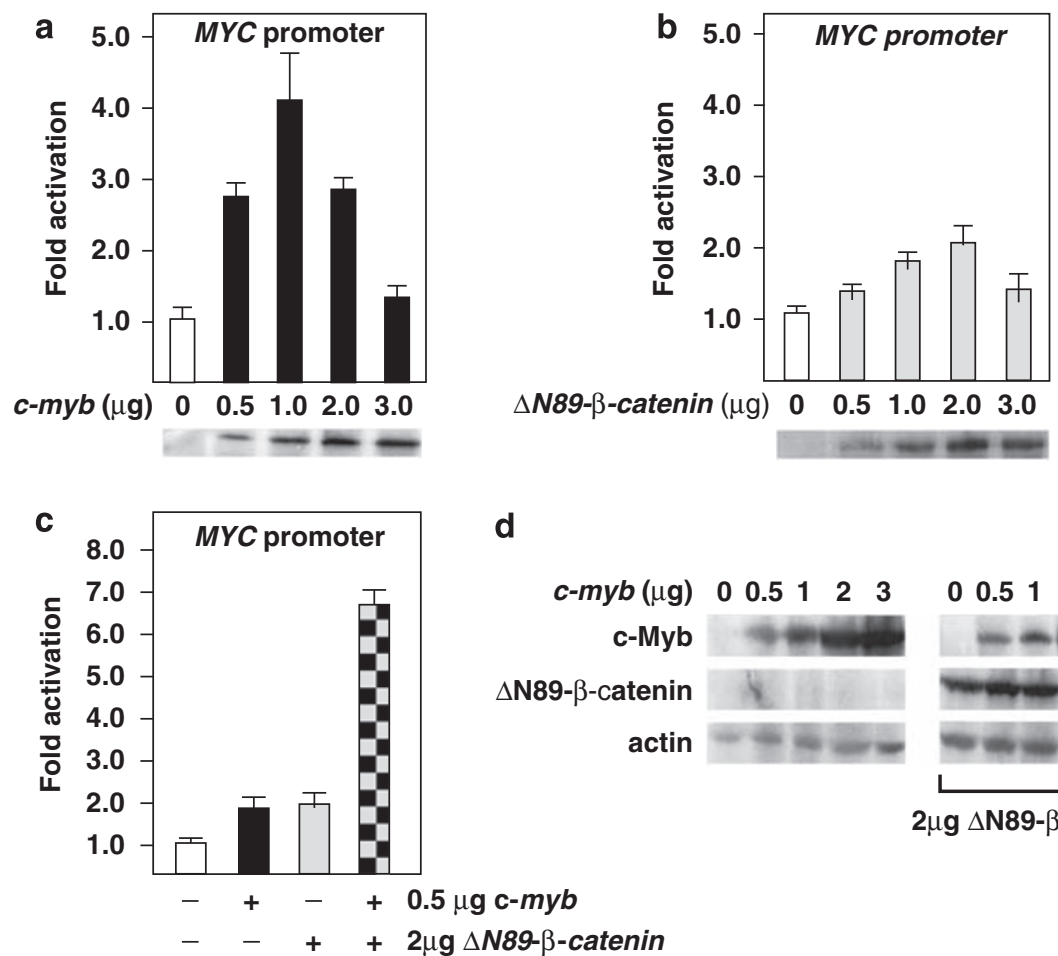

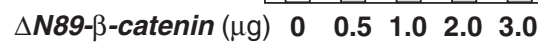

Figure 5 Suboptimal amounts of c-Myb cooperate with activated $\beta$-catenin to transactivate the MYC promoter in HEK293 cells. (a) c-Myb activates the MYC reporter to a maximum of approximately fourfold whereas (b) activated $\beta$-catenin achieves at best an approximately twofold increase in reporter activity. (c) When maximum levels of activated $\beta$-catenin and minimum levels of c-Myb are combined activation is now approximately sevenfold. Activation of the MYC promoter is significantly greater when c-Myb and activated $\beta$-catenin are combined compared to the individual effectors alone $\left(t\right.$-test; $\left.P<1 \times 10^{-5}\right)$. (d) Western blots showing the expression of the c-Myc-epitope-tagged $\Delta$ N89- $\beta$-catenin, C-Myb, and a loading control pan-actin

submaximal amounts of c-Myb/MYB and activated $\beta$-catenin provided only minimal stimulation of the reporter construct. In combination, however, these same levels of c-Myb and activated $\beta$-catenin gave a 6.5 -fold increase in reporter stimulation, suggesting a cooperative activity exists between $\mathrm{C}-\mathrm{Myb}$ and $\beta$-catenin in regulating the MYC promoter (Figure $5 \mathrm{c}$ ). Furthermore, the pattern of activation observed in Figure $5 \mathrm{c}$ is maximal and sustainable, such that adding more c-Myb does not lead to the reduction in activity normally associated with excess c-Myb (Figure 5a; data not shown). Moreover, the levels of MYB expression are unchanged in the presence or absence of activated $\beta$-catenin (Figure $5 \mathrm{~d}$ ). These results thus demonstrate that MYB enhances the capacity of activated $\beta$-catenin to transactivate the Wnt target 
$M Y C$. In addition, the presence of activated $\beta$-catenin overcomes the apparent inhibitory effects of c-Myb on MYC promoter activity when c-Myb is present in excess.

MYB and $\beta$-catenin converge in regulating endogenous MYC expression. We next examined whether cooperation between activated $\beta$-catenin and MYB extended to the regulation of endogenous $M Y C$. In a result mirroring those from the reporter studies, transfection of submaximal amounts of $c-M y b$ led to a slight increase in the level of MYC mRNA (Figure 6a). Activated $\beta$-catenin was also able to induce endogenous $M Y C$ mRNA modestly (Figure 6a). Combining the two transcription factors however yielded a more immediate, greater and sustainable increase

a

mRNA

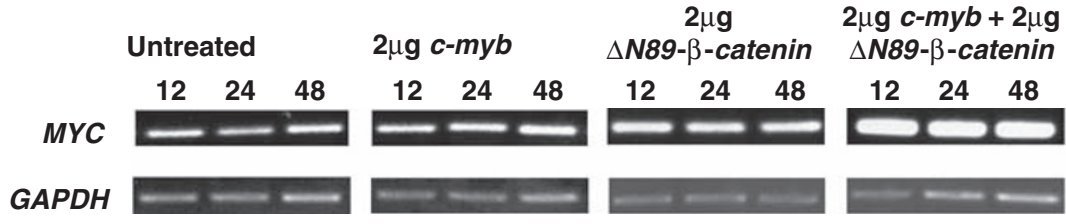

b

Protein

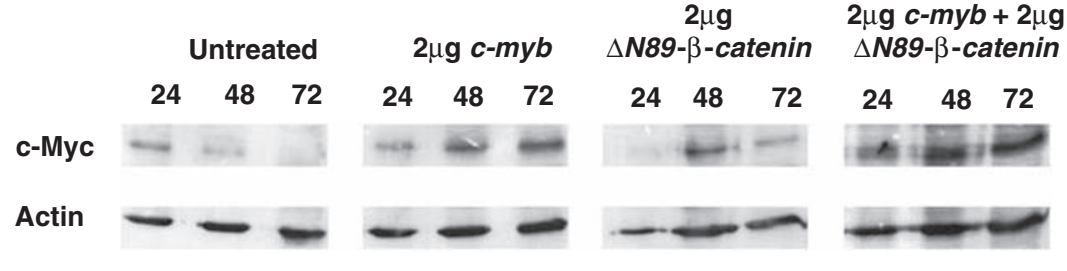

C

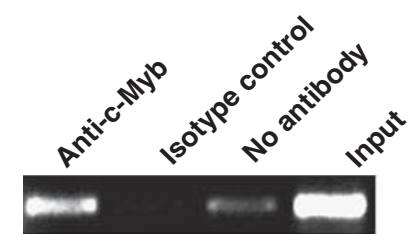

$c-m y b$ transfected

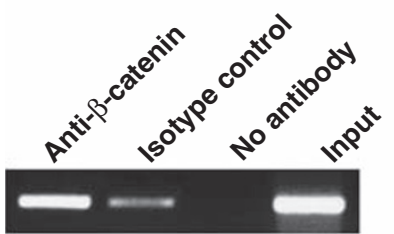

$\beta$-catenin transfected

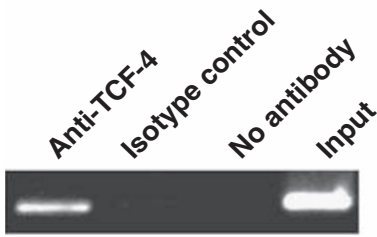

TCF-4 transfected

d

MYC

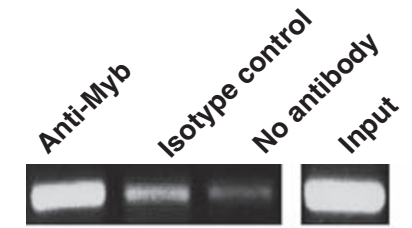

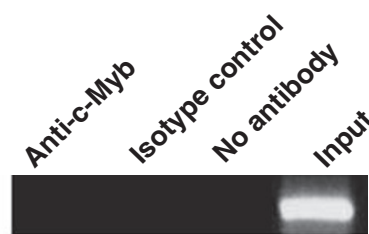

untransfected

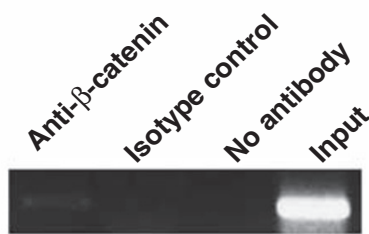

untransfected

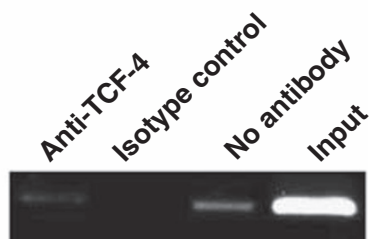

untransfected

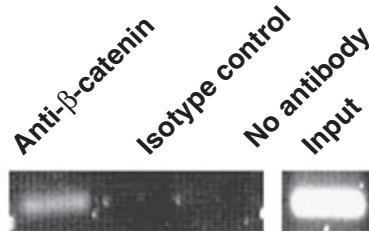

Figure $6 \mathrm{c}-\mathrm{Myb}$ and activated $\beta$-catenin cooperate in activating endogenous MYC and bind to the endogenous MYC promoter. HEK293 cells were transfected with constructs for c-Myb, activated $\beta$-catenin, or a combination of both and then harvested for total RNA at the times indicated after transfection. (a) Total RNA was reversetranscribed, then subsequently used in PCR reactions to detect changes in the level of MYC mRNA. Housekeeping gene GAPDH was used to control for loading of cDNA for the PCR reactions. (b) Proteins were extracted from HEK293 cells transfected as in (a) and probed for changes in the level of c-Myc. Pan-actin was used to control for the loading of protein. (c) C-Myb, TCF4, and $\beta$-catenin are recruited to the MYC promoter in transfected HEK293 epithelial cells and (d) c-Myb and $\beta$-catenin in the case of Colo201 colorectal cancer cells as determined by ChIP assays 
(approximately sixfold; determined by densitometry scans) in MYC mRNA expression than that achieved by the individual effectors alone. Changes in MYC mRNA levels associated with the expression of $M Y B$ and activated $\beta$-catenin were also reflected as an increase in c-Myc protein (Figure 6b). It is apparent from these results that MYB and activated $\beta$-catenin also cooperate to support robust expression of endogenous MYC.

MYB and activated $\beta$-catenin bind to the endogenous MYC promoter. c-Myb and activated $\beta$-catenin may cooperate in regulating $M Y C$ by associating together at the cellular target gene promoter. To evaluate this, chromatin immunoprecipitation (ChIP) assays were carried out in HEK293 cells transfected with expression constructs for $\mathrm{c}-\mathrm{Myb}$ and $\beta$-catenin. These experiments showed that both proteins were recruited to the MYC promoter (Figure $6 c$ ). In the absence of transfected proteins, very little $M Y C$ promoter was detected in ChIP lysates, consistent with the minimal $\mathrm{c}-\mathrm{Myb} / \mathrm{MYB}$ expression and low amounts of endogenous nuclear $\beta$-catenin in this cell line.

To determine whether endogenous $\mathrm{c}-\mathrm{Myb}$ and $\beta$-catenin bind to the genomic MYC promoter in human CRC cells, ChIP assays were performed in Colo201 cells. These cells express abundant levels of $M Y B^{18}$ and $M Y C^{22}$ and have an activated Wnt pathway through $A P C$ mutation. ${ }^{6}$ As shown in Figure $6 \mathrm{c}$, both c-Myb and $\beta$-catenin are enriched at the $M Y C$ promoter in these CRC cells. Numerous attempts were made to examine whether $\mathrm{c}-\mathrm{Myb}$ and $\beta$-catenin, with or without TCF4, are able to form an endogenous complex in CRC cells or in HEK293 cells when overexpressed. However, no evidence for such complexes was obtained, although binding of $\beta$-catenin to TCF4 was readily established (data not shown). These observations indicate that that both transcription factors most likely engage the MYC promoter independently of each other. To further understand the mechanism by which cooperation between the two factors occurs, we assessed acetylation at the $M Y C$ promoter using an antibody directed toward a motif correlated with transcriptional activation, acetylated lysine 27 of histone H3. We found increased acetylated histone H3 (lysine 27) associated with the binding of both factors, but in particular c-Myb (data not shown). In a broader context, these data provide additional support for the proposition that the activation of $M Y C$ expression by deregulated Wnt signaling is more readily achieved in the presence of c-Myb.

\section{Discussion}

The Wnt pathway has an early and prominent function in CRC genesis through mutations in $A P C$ or $\beta$-catenin. ${ }^{3,4,23}$ Analysis of $A P C^{\mathrm{Min} /+}$ mice and their corresponding predisposition to intestinal adenoma formation has allowed the cellular and molecular aspects of human familial adenomatous polyposis (FAP) to be understood. ${ }^{24}$

The biology of adenoma formation needs to be considered in the context of how crypts are generated and maintained. In this regard, the Wnt pathway, ${ }^{25-27} c-M y b b^{2}$ and $M Y C^{28,29}$ are particularly important. We observed that the normal kinetics of adenoma formation in $A P C^{\mathrm{Min} /+}$ mice is correspondingly and significantly delayed when $c-m y b$ is haploinsufficient. This is likely because of the need to drive strong expression of important gene targets such as $M Y C$, as shown in the current study. It has been reported that intestine-specific knockout of $c-m y c$ reduces adenoma formation in $A P C^{\mathrm{Min} /+}$ mice. ${ }^{30} \mathrm{We}$ found a similar phenomenon in $A P C^{\mathrm{Min} /+}$ mice when one allele of $c-m y b$ is deleted. This is an especially important observation given that $M Y C$ is a common target for both MYB and the Wnt pathway in CRC. Certainly, deletion of either $c-m y b$ or $c-m y c$ has a critical effect on colonic crypt development, ${ }^{2,31,32}$ whereas $c-M y b$ is additionally necessary for appropriate maintenance of adult crypt homeostasis. ${ }^{2}$ As a corollary, $c-m y b$ or $c-m y c$ expression is highly elevated in $A P C^{\mathrm{Min} /+}$ adenomas in the SI and colon indicating involvement of these in the inappropriate expansion of epithelial cells. The more slowly forming adenomas in $A P C^{\mathrm{Min} /+} \times c-m y b^{+/-}$ mice showed a correspondingly reduced level of both $c-m y b$ and $c$-myc expression. Whether this finding reflects the availability of a single $c$-myb allele for activation in adenoma-prone $A P C^{M i n /+}$ intestinal epithelia is currently unclear. However, when these observations are considered together, it is clear that $c-m y b$ and $c-m y c$ are required for normal crypt biology, but when overexpressed are associated with carcinogenesis.

Given that $M Y C$ is normally targeted by both the MYB and Wnt pathways, these data suggest a prospective mechanism for cooperation in which activated Wnt signaling leads to upregulation of $M Y B$, making it available for cooperative activation of target genes such as MYC. Previous work by others highlighted $M Y B$ as a potential Wnt target gene. ${ }^{20}$ However, we did not observe activation of either the MYB promoter or endogenous gene by an activated form of $\beta$-catenin. This discrepancy between our results and those of van de Wetering et al. may derive from the normal cellular biology of c-Myb/MYB. Expression of dominant-negative TCF4 in CRC cells causes cellular differentiation, a process that occurs in concert with decreased MYB expression. Nevertheless, we cannot at this stage rule out $M Y B$ as a bona fide Wnt target gene in CRC. It is possible that the variation in findings stems from the different cell types used in each study.

c-Myb requires cooperating factors in a number of circumstances to exert its full transactivation potential. For instance, c-Myb is known to work in partnership with a number of proteins, including CBP, the C/EBP $\beta$ family member NF-M, and $\mathrm{p} 100$, in regulating hemopoietic genes such as mim-1 (reviewed in Ramsay and Gonda ${ }^{1}$ ). The present work extends this list of $\mathrm{c}-\mathrm{Myb}$ partners to include $\beta$-catenin. We have confirmed previous reports that $\beta$-catenin alone activates the $M Y C$ promoter, but extended these observations by demonstrating that convergence with MYB leads to a more robust level of $M Y C$ promoter activity as well as expression from the endogenous gene locus. Our attempts to show direct interaction between the two factors were unsuccessful. The implication from this was that cooperative transactivation by the two factors is not achieved through physical association with each other, but rather through a mechanism that perhaps involves the independent binding of each factor to the target promoter, as shown in our ChIP assays. In further support of this assertion, ChIP assays against a histone motif correlated with transactivation showed increased acetylation at the $M Y C$ 
promoter associated with the presence of both factors, consistent with the increased levels of endogenous $M Y C$ mRNA and protein.

The potential that $\mathrm{c}-\mathrm{Myb} / \mathrm{MYB}$ and activated $\beta$-catenin cooperate in regulating other genes central to $\mathrm{CRC}$ has also been considered. One gene of particular interest was cyclooxygenase 2 (COX-2). The COX-2 promoter has both TCF4/LEF $-1^{33,34}$ and MYB binding sites within it promoter region, whereas its counterpart $C O X-1$ has none. ${ }^{35}$ Expression of Cox-2 is increased markedly in $A P C^{\mathrm{Min} /+}$ intestinal adenomas (Supplementary Figure $3 a$ ) as reported by others. ${ }^{36,37}$ We observed cooperative induction of the human COX-2 promoter in the presence of submaximal levels of MYB with activated $\beta$-catenin, recapitulating the data described here for MYC (Supplementary Figure $3 b-d$ ). This indicates that the cooperative interaction between MYB and activated $\beta$-catenin may extend beyond $M Y C$ alone to include the regulation of other genes important to adenoma formation and progression.

In conclusion, we have established a relationship between the two most commonly activated pathways in CRC in the generation of intestinal adenomas, a process that appears to function by cooperative regulation of CRC genes such as $M Y C$. This cooperative mechanism of activation would be possible at the earliest stages of colonic crypt epithelial cell transformation where $A P C$ mutations are thought to initiate $\mathrm{CRC}$, because $M Y B$ expression is a feature of normal colonocytes and thus available to work in cooperation with elevated levels of $\beta$-catenin. This work highlights the importance of discovering modes of therapeutic targeting of inappropriate $M Y B$ expression. ${ }^{1}$

\section{Materials and Methods}

Mice. $\mathrm{C} 57 \mathrm{BI} / 6 A P C^{\min /+}$ mice harboring an $A p c$ allele mutation that encodes a truncated protein of 850 amino acids and $c-m y b^{+/-}$knockout mice were interbred to generate compound heterozygous mice. They were observed for any signs intestinal bleeding or ill health according the Peter MacCallum Cancer Centre Animal Experimentation Ethics Committee regulations. Sick mice were killed and examined for the presence of adenomas in the colon and Sls. Adenomas and histologically normal mucosa were collected and processed for total RNA using Trizol (Invitrogen).

cDNA microarray expression analysis. A gene expression database representing 229 tumor samples belonging to 13 histological types has been developed for the classification of different cancers. ${ }^{38}$ Following intensity-based (LOWESS) and per gene median normalization of the array data, fold-change ratios for the genes MYB, MYC, and $\beta$-catenin (CTNNB1) were visualized across ordered cancer types using the programs Cluster and Treeview. All gene probes were confirmed by DNA sequencing.

Reporter assays. HEK293 or NIH3T3 cells were transfected with a combination of either $0.2 \mu \mathrm{g}$ of CAT or $1 \mu \mathrm{g}$ of luciferase reporter plasmid (pc-mycCAT, pTOPFlash, or pFOPFlash, $0.5-3 \mu \mathrm{g}$ of effector plasmid (pACT-c-myb or $p c D N A 3.1-\Delta N 89-\beta$-catenin) and $0.33 \mu \mathrm{g}$ of transfection efficiency plasmid ( $p S V 40$ $\beta$-galactosidase) using Metafectene (Biontex) according to the manufacturer's instructions. The MYB promoter construct has been described in detail elsewhere. ${ }^{39}$

Western blotting. Transfection of cells involved correspondingly higher amounts of plasmid effector DNAs per flask to recapitulate the ratios of effector DNAs to cell numbers used in the reporter studies. Proteins were partitioned into nuclear and cytoplasmic fractions by differential centrifugation in lysis buffer before separation on $10 \%$ polyacrylamide/SDS gels and transfer to PVDF membrane. Membranes were blocked in $10 \%$ non-fat skim milk powder and then probed with one of the following antibodies made up in 1\% gelatin: mouse anti-c-Myb 1.1
(1:500), mouse anti-c-Myc tag, mouse anti-pan actin (1:2500; ICN Biomedical), and mouse anti- $\beta$-catenin. After washing, the membranes were probed with $a$ goat anti-mouse secondary antibody conjugated to alkaline phosphatase $(1: 2500$; Bio-Rad). Blots were developed using 5-bromo-4-chloro-3'-indolyphosphate $p$-toluidine salt and nitro-blue tetrazolium chloride reagents (Sigma).

MYB knockdown by RNA interference. The doxycycline-inducible lentiviral shRNA vector $p L V T S H$ will be fully described elsewhere (Barry et al., in preparation). In brief, vectors encoding an MYB shRNA 5'-GAACCUCUUACA AUUUGCAGAAACACUUUCAUGAGAAGUGUUUCUGCAUUGUGUAAGAGGUU CUU- $3^{\prime}$ (with the bold sequences corresponding to sense and antisense MYB mRNA, respectively) and a scrambled control shRNA 5'-AUAAGAAU GUCCAUC AGUUACGCCAUAUUCAUGAGAUAUGGCGUAACUGAUGGACAUUCUUAUUU- $3^{\prime}$ were used. Lentivirus was generated by co-transfection of HEK293T cells with packaging plasmids using Lipofectamine 2000 (Invitrogen) as directed by the manufacturer. The supernatant was collected after $48 \mathrm{~h}$, filtered through a $0.45 \mu \mathrm{m}$ filter before being used to transduce Colo201 cells. These cells were FACS-sorted based on expression of pLVTSH-encoded eGFP. Cell were allowed to expand and then treated with $1 \mu \mathrm{g} / \mathrm{ml}$ doxycycline (Sigma) for 3 days. A sample of each culture was collected, washed in PBS and placed in Trizol, and subsequently processed for total RNA. MYB and MYC knockdown efficiency was assessed by Q-RT-PCR

Chromatin Immunoprecipitation assays. Approximately $1 \times 10^{6}$ HEK293 cells were plated out in $100 \mathrm{~mm}$ dishes and transfected with $4 \mu \mathrm{g}$ of one of the following constructs: pcDNA3.1- $4 N 89-\beta$-catenin, pcDNA1-TCF4, or pACT-c-myb. The same number of cells were also plated and left as untransfected controls. For examination of endogenous MYC promoter occupancy in CRC cells, approximately $1 \times 10^{6}$ Colo201 cells were plated in $100 \mathrm{~mm}$ dishes. ChIP assays were carried out $72 \mathrm{~h}$ after transfection for HEK293 cells or $72 \mathrm{~h}$ after plating for Colo201 cells. Briefly, cells were fixed with formaldehyde, washed, and subsequently lysed. The resulting lysates were sonicated on ice to yield DNA fragments of an appropriate size (300-1000 bp). After preclearing with Protein A Sepharose beads (Amersham Biosciences), samples were treated with one of the following antibodies to assess binding to the MYC promoter: mouse anti-Myb (clone 1.1, 1: 500); TCF4 antibody (Santa Cruz Biotechnology); and mouse anti- $\beta$-catenin (Signal Transduction Laboratories). A mouse anti-pan actin antibody and rabbit serum (Zymed) served as isotype controls. Antibody-protein-DNA complexes were collected using Protein A Sepharose beads and washed to remove nonspecifically bound protein-DNA adducts. The formaldehyde cross-links were reversed before the immunoprecipitates were assessed by PCR. ChIP samples were used undiluted and subjected to 27 cycles of PCR at $60{ }^{\circ} \mathrm{C}$. Approximately $12 \%$ of the original sample was taken as the input control and subjected to the same PCR thermocycling. The following primers were used for amplification: for transfected HEK293 and Colo201cell studies-forward, 5'-GCCTGCGATGATTTATACTCACAG-3'; reverse, $5^{\prime}$-CGGAGATTAGCGAGAGAGGATC- $3^{\prime}$. These were designed using Primer Express software from Applied Biosystems.

RT-PCR analysis of endogenous MYC and MYB expression. The effect of ectopic $c-M y b$ and activated $\beta$-catenin on the transcriptional regulation of genomic MYC and MYB was assessed by RT-PCR. Total RNA was extracted from HEK293 cells at various time points after transfection with the different expression constructs for MYB and activated $\beta$-catenin (see above) using Trizol (Invitrogen). Extracted RNA was DNAse-1-treated and subsequently used to synthesize cDNA before assessment of changes in expression by conventional PCR. The primers and annealing conditions used were-MYC: forward, $5^{\prime}$-CAGCTGCTTAGACGCTGG ATT-3'; reverse, 5'-GTAGAAATACGGCTGCACCGA-3', 27 cycles of PCR at $60^{\circ} \mathrm{C}$; MYB: forward, $5^{\prime}$-GCCAATTATCTCCCGAATCGA-3'; reverse, $5^{\prime}$-ACCAAC GTTTCGGACCGTA-3'; GAPDH: forward, 5'-AGCCTTCTCCATGGTGGTGAAG AC-3'; reverse, $5^{\prime}$-CGGAGTCAACGGATTTGGTCGTAT- $3^{\prime}$, 22 cycles of PCR at $60^{\circ} \mathrm{C}$

Expression of endogenous c-myc, c-myb, and cox-2 in $A P C^{\min /+}$ mouse adenomas and normal tissue - c-myc: forward, $5^{\prime}$-AAGGCCCCCAAGGTAGTGA-3'; reverse, 5'-TGCTCGTCTGCTTGAATGGA-3'; c-myb: forward, 5'-AATTATCTGCCCAACCGG-3'; reverse, 5'-AGACCAACGCTTCGGACC-3'; cox-2: forward, 5'-AGAA GGAAATGGCTGCAGAA-3'; reverse, 5'-CCCCAAAGATAGCATCTGGA-3'.

Chromatin immunoprecipitation assays. Q-RT-PCR was used to examine changes in acetylation levels at the endogenous MYC promoter associated with the binding of MYB and $\beta$-catenin. Approximately $1 \times 10^{6} \mathrm{HEK} 293$ cells 
were plated out in $100 \mathrm{~mm}$ dishes and transfected with $4 \mu \mathrm{g}$ of either $p c D N A 3.1$. $\triangle N 89-\beta$-catenin or $p A C T-c-M y b$ alone or in combination. The same number of cells were also plated and used as untransfected controls. ChIP assays were carried out $72 \mathrm{~h}$ after transfection. After fixation and sonication of the DNA, samples were precleared with Protein $A$ Sepharose beads and treated with a rabbit acetylatedlysine27-specific antibody (Upstate Biotechnology). Rabbit serum (Zymed) served as an isotype control. Antibody-protein-DNA complexes were collected using Protein A Sepharose beads, washed, and the formaldehyde cross-links reversed before the immunoprecipitates were assessed by PCR. ChIP samples were diluted 15 -fold in $\mathrm{dH}_{2} \mathrm{O}$ before use. Reaction mixtures and thermocycling were performed using SYBR Green according to the manufacturer's instructions in a PerkinElmer real-time PCR machine, model 7000 (Applied Biosystems). Primer sets were used to generate $100 \mathrm{bp}$ amplicons and designed using Primer Express software from Applied Biosystems. Primer set 1: forward, 5'-CTGGAAGGCAGCCAAATTTTA-3'; reverse, $5^{\prime}$-AAAATGCATCGATTCTGATCAAAG-3'. Primer set 2: forward, $5^{\prime}$-AGG ACAAGGATGCGGTTTGT-3'; reverse, 5'-CTACGCGCGCCTACCATTT- $3^{\prime}$. Forty cycles of PCR were used at a temperature of $60^{\circ} \mathrm{C}$. Analysis of the primary data was undertaken as described. ${ }^{40}$

Acknowledgements. This work was supported by a fellowship (RGR) and grants from the NHMRC, Australia. We thank Alla Mirochnik and Tony Li (Department of Microbiology and Department of Molecular Genetics, University of California, Irvine, CA, USA) for the generous provision of reagents and time. Suggestions by Dr. Ross Hannan were also of great assistance during the preparation of the paper.

1. Ramsay RG, Gonda TJ. MYB function in normal and cancer cells. Nat Rev Cancer 2008; 8 523-534.

2. Malaterre J, Carpinelli M, Ernst M, Alexander W, Cooke M, Sutton S et al. c-Myb is required for progenitor cell homeostasis in colonic crypts. Proc Natl Acad Sci USA 2007; 104: 3829-3834.

3. Polakis P. Wnt signaling and cancer. Genes Dev 2000; 14: 1837-1851.

4. Giles $\mathrm{RH}$, van Es JH, Clevers $\mathrm{H}$. Caught up in a Wnt storm: Wnt signaling in cancer. Biochim Biophys Acta 2003; 1653: 1-24.

5. Staal FJ, Noort Mv M, Strous GJ, Clevers HC. Wnt signals are transmitted through $\mathrm{N}$-terminally dephosphorylated beta-catenin. EMBO Rep 2002; 3: 63-68.

6. Ilyas M, Tomlinson IP, Rowan A, Pignatelli M, Bodmer WF. Beta-catenin mutations in cell lines established from human colorectal cancers. Proc Natl Acad Sci USA 1997; 94 10330-10334.

7. Kinzler KW, Vogelstein B. Lessons from hereditary colorectal cancer. Cell 1996; 87 159-170.

8. Powell SM, Zilz N, Beazer-Barclay Y, Bryan TM, Hamilton SR, Thibodeau SN et al. APC mutations occur early during colorectal tumorigenesis. Nature 1992; 359: 235-237.

9. Sparks AB, Morin PJ, Vogelstein B, Kinzler KW. Mutational analysis of the APC/betacatenin/Tcf pathway in colorectal cancer. Cancer Res 1998; 58: 1130-1134.

10. Yekkala K, Baudino TA. Inhibition of intestinal polyposis with reduced angiogenesis in ApcMin/+ mice due to decreases in c-Myc expression. Mol Cancer Res 2007; 5 1296-1303.

11. He TC, Sparks AB, Rago C, Hermeking H, Zawel L, da Costa LT et al. Identification of C-MYC as a target of the APC pathway. Science 1998; 281: 1509-1512.

12. Howe LR, Subbaramaiah K, Chung WJ, Dannenberg AJ, Brown AM. Transcriptional activation of cyclooxygenase-2 in Wnt-1-transformed mouse mammary epithelial cells. Cancer Res 1999; 59: 1572-1577.

13. Shtutman M, Zhurinsky J, Simcha I, Albanese C, D'Amico M, Pestell R et al. The cyclin D1 gene is a target of the beta-catenin/LEF-1 pathway. Proc Natl Acad Sci USA 1999; 96: 5522-5527

14. Nakagoshi H, Kanei-Ishii C, Sawazaki T, Mizuguchi G, Ishii S. Transcriptional activation of the c-myc gene by the c-myb and B-myb gene products. Oncogene 1992; 7: 1233-1240.

15. Schmidt M, Nazarov V, Stevens L, Watson R, Wolff L. Regulation of the resident chromosomal copy of c-myc by c-Myb is involved in myeloid leukemogenesis. Mol Cell Biol 2000; 20: 1970-1981.

16. Blanc V, Henderson JO, Newberry RD, Xie Y, Cho SJ, Newberry EP et al. Deletion of the AU-rich RNA binding protein Apobec-1 reduces intestinal tumor burden in $\mathrm{Apc}(\mathrm{min})$ mice. Cancer Res 2007; 67: 8565-8573.
17. Boussioutas A, Li H, Liu J, Waring P, Lade S, Holloway AJ et al. Distinctive patterns of gene expression in premalignant gastric mucosa and gastric cancer. Cancer Res 2003; 63 2569-2577.

18. Alitalo K, Winqvist R, Lin CC, de la Chapelle A, Schwab M, Bishop JM. Aberrant expression of an amplified c-myb oncogene in two cell lines from a colon carcinoma. Proc Natl Acad Sci USA 1984; 81: 4534-4538.

19. Trainer DL, Kline T, McCabe FL, Faucette LF, Feild J, Chaikin M et al. Biological characterization and oncogene expression in human colorectal carcinoma cell lines. Int J Cancer 1988; 41: 287-296.

20. van de Wetering M, Sancho E, Verweij C, de Lau W, Oving I, Hurlstone A et al. The betacatenin/TCF-4 complex imposes a crypt progenitor phenotype on colorectal cancer cells. Cell 2002; 111: 241-250.

21. Nicolaides NC, Gualdi R, Casadevall C, Manzella L, Calabretta B. Positive autoregulation of $c$-myb expression via Myb binding sites in the $5^{\prime}$ flanking region of the human c-myb gene. Mol Cell Biol 1991; 11: 6166-6176.

22. Lee MO, Han SY, Jiang S, Park JH, Kim SJ. Differential effects of retinoic acid on growth and apoptosis in human colon cancer cell lines associated with the induction of retinoic acid receptor beta. Biochem Pharmacol 2000; 59: 485-496.

23. Bienz M, Clevers H. Linking colorectal cancer to Wnt signaling. Cell 2000; 103 311-320.

24. Moser AR, Dove WF, Roth KA, Gordon JI. The Min (multiple intestinal neoplasia) mutation: its effect on gut epithelial cell differentiation and interaction with a modifier system. $J$ Cell Biol 1992; 116: 1517-1526.

25. Andreu P, Colnot S, Godard C, Gad S, Chafey P, Niwa-Kawakita M et al. Crypt-restricted proliferation and commitment to the Paneth cell lineage following Apc loss in the mouse intestine. Development 2005; 132: 1443-1451.

26. Batlle E, Henderson JT, Beghtel H, van den Born MM, Sancho E, Huls G et al. Beta-catenin and TCF mediate cell positioning in the intestinal epithelium by controlling the expression of EphB/ephrinB. Cell 2002; 111: 251-263.

27. Hoffman J, Kuhnert F, Davis CR, Kuo CJ. Wnts as essential growth factors for the adult small intestine and colon. Cell Cycle 2004; 3: 554-557.

28. Bettess MD, Dubois N, Murphy MJ, Dubey C, Roger C, Robine S et al. c-Myc is required for the formation of intestinal crypts but dispensable for homeostasis of the adult intestinal epithelium. Mol Cell Biol 2005; 25: 7868-7878.

29. Muncan V, Sansom OJ, Tertoolen L, Phesse TJ, Begthel H, Sancho E et al. Rapid loss of intestinal crypts upon conditional deletion of the Wnt/Tcf-4 target gene c-Myc. Mol Cell Biol 2006; 26: 8418-8426.

30. Ignatenko NA, Holubec $\mathrm{H}$, Besselsen DG, Blohm-Mangone KA, Padilla-Torres JL, Nagle $\mathrm{RB}$ et al. Role of c-Myc in intestinal tumorigenesis of the ApcMin/+ mouse. Cancer Biol Ther 2006; 5: 1658-1664.

31. Zorbas M, Sicurella C, Bertoncello I, Venter D, Ellis S, Mucenski ML et al. c-Myb is critical for murine colon development. Oncogene 1999; 18: 5821-5830.

32. Sansom OJ, Reed KR, Hayes AJ, Ireland H, Brinkmann H, Newton IP et al. Loss of Apc in vivo immediately perturbs Wnt signaling, differentiation, and migration. Genes Dev 2004 18: $1385-1390$

33. Araki $\mathrm{Y}$, Okamura $\mathrm{S}$, Hussain SP, Nagashima M, He P, Shiseki $\mathrm{M}$ et al. Regulation of cyclooxygenase-2 expression by the Wnt and ras pathways. Cancer Res 2003; 63 728-734.

34. Kim SJ, Im DS, Kim SH, Ryu JH, Hwang SG, Seong JK et al. Beta-catenin regulates expression of cyclooxygenase-2 in articular chondrocytes. Biochem Biophys Res Commun 2002; 296: 221-226.

35. Ramsay RG, Friend A, Vizantios $Y$, Freeman R, Sicurella $C$, Hammett $F$ et al. Cyclooxygenase-2, a colorectal cancer nonsteroidal anti-inflammatory drug target, is regulated by C-MYB. Cancer Res 2000; 60: 1805-1809.

36. Oshima M, Dinchuk JE, Kargman SL, Oshima H, Hancock B, Kwong E et al. Suppression of intestinal polyposis in Apc delta716 knockout mice by inhibition of cyclooxygenase 2 (COX-2). Cell 1996; 87: 803-809.

37. Williams CS, Luongo C, Radhika A, Zhang T, Lamps LW, Nanney LB et al. Elevated cyclooxygenase-2 levels in Min mouse adenomas. Gastroenterology 1996 111: 1134-1140.

38. Tothill RW, Kowalczyk A, Rischin D, Bousioutas A, Haviv I, van Laar RK et al An expression-based site of origin diagnostic method designed for clinical application to cancer of unknown origin. Cancer Res 2005; 65: 4031-4040.

39. Hugo H, Cures A, Suraweera N, Drabsch Y, Purcell D, Mantamadiotis T et al. Mutations in the MYB intron I regulatory sequence increase transcription in colon cancers. Genes Chromosomes Cancer 2006; 45: 1143-1154.

40. Christenson LK, Stouffer RL, Strauss III JF. Quantitative analysis of the hormone-induced hyperacetylation of histone $\mathrm{H} 3$ associated with the steroidogenic acute regulatory protein gene promoter. J Biol Chem 2001; 276: 27392-27399. 